\title{
Risk versus economic performance in a mixed fishery
}

\author{
Gourguet Sophie ${ }^{1,2,5,{ }^{*}}$, Thebaud Olivier ${ }^{1,5}$, Dichmont C. ${ }^{1}$, Jennings S. ${ }^{4}$, Little L. R. ${ }^{3}$, Pascoe S. ${ }^{1}$, \\ Deng R. A. ${ }^{1}$, Doyen L. ${ }^{2}$
}

${ }^{1}$ CSIRO, Marine \& Atmospher Res, Dutton Pk, Qld 4102, Australia.

${ }^{2}$ CNRS MNHN, CERSP UMR 7204, F-75005 Paris, France.

${ }^{3}$ CSIRO Marine \& Atmospher Res, Hobart, Tas 7001, Australia.

${ }_{5}^{4}$ Univ Tasmania, Sch Econ \& Finance, Hobart, Tas 7001, Australia.

${ }^{5}$ Ifremer, france

* Corresponding author : Sophie Gourguet, tel.: + 33685801433 ;

email address : sophie.gourguet@gmail.com

\begin{abstract}
:
Balancing bio-economic risks and high profit expectations is often a major concern in fisheries management. We examine this trade-off in the context of the Australian Northern Prawn Fishery (NPF). The fishery derives its revenue from different prawn species with different dynamics and recruitment processes. A multi-species bio-economic and stochastic model is used to examine the trade-offs between mean profitability of the fishery and its variance, under a range of economic scenarios, fishing capacities and distributions of fishing effort across the various sub-fisheries that comprise the NPF. Simulation results show that the current fishing strategy diversifying catch across sub-components of the fishery entails a compromise between expected performance and risk. Furthermore, given the current economic conditions, increases in fleet size would improve the expected economic performance of the fishery, but at the cost of increased variability of this performance.
\end{abstract}

\section{Highlights}

- Balancing economic returns and their variability is a concern in fisheries management. Nature of this trade-off is examined for the Australian Northern Prawn Fishery. Analyses are based on a multispecies stochastic bio-economic model. Fishing effort is allocated between predictable and highly fluctuating components. Current effort strategy appears as a compromise between average performance and risk.

Keywords: Bio-economic modelling, Uncertainty, Risk-performance trade-offs, Fishing strategy, Northern Prawn Fishery 


\section{Introduction}

Globally, many capture fisheries do not achieve their full economic potential and are subject to excess capacity (Munro, 2010). For some fisheries, this may be due to failure in regulating the race to fish. Other fisheries may be managed to achieve Maximum Sustainable Yield (MSY), rather than Maximum Economic Yield (MEY). In some cases, social considerations may dominate the management decision process leading to the approval of even higher levels of capacity. In other cases, differences between observed harvesting levels of individual species and the levels which would ensure MEY may be related to the fact that commercial fishers operate across a range of species, with varying ability to target these species separately, leading to difficulties in identifying optimal fishery-wide levels of fishing capacity and allocation of fishing effort. Moreover, revenues from fisheries may vary greatly from year to year owing to natural variation in fish stocks (Kasperski and Holland, 2013) that cannot be predicted with any reliability, leading to varying levels of economic risks for fishing operators (Sethi, 2010). While maximising economic yield is usually seen as a desirable objective for fisheries management, industry stakeholders usually also value stability over time. This may be due to risk aversion, but also to the need to maintain markets, avoid market saturation and guide investment decisions relating to non-malleable capital (Holland and Herrera, 2009). Successful fisheries management should therefore identify and cope with risk to minimize the effects of unpredictable variability (Sethi, 2010). Indeed, as expressed by Hilborn et al. (2001): "if we are to succeed at management - if we are to maintain stable fishing communities - we have to begin to manage risk". The process of dealing with risk in fisheries management involves the formulation of advice for fisheries managers in a way that conveys the possible consequences of uncertainty, but also handles the ways in which managers take uncertainty into account in making decisions (Francis and Shotton, 1997).

In multi-species fisheries, the different fish stocks contributing to the overall catch may present different levels of natural variability, such that the choice of fishing strategies can be 
associated with trade-offs between mean and variance of the fishery's economic yield. Portfolio theory focuses on the selection of assets (such as species) to create a bundle that provides the greatest expected economic performance (such as catch or annual income) at the least variation about the expected performance (Markowitz, 1952, Roy, 1952). Mean-variance analysis, which is consistent with portfolio theory, is particularly important in finance (Epstein, 1985). While portfolio effects have been studied for fisheries management (Sanchirico et al., 2008, Sethi, 2010), mean-variance analyses have not been explicitly applied in the context of allocating effort in a multi-species fishery.

This article focuses on a mean-variance analysis of inter-temporal profits of a fishery in which the set of target species have different levels of environmentally driven variability in recruitment. The study is based on a dynamic bio-economic modelling approach, in line with capital theory (Clark and Munro, 1975), where fish stocks are taken as natural capital assets and where net present value of profits plays a major role. The analysis is applied to the case of the Northern Prawn Fishery (NPF) in Australia. The bio-economic model is used to explore the trade-offs between mean performance and risk associated with alternative managements, taking into account the distribution of fishing effort across its sub-components and different assumptions regarding changes in fuel and prawn prices. Simulation results show that the economic performance of the fishery could be improved by increasing the capacity of the fleet, but at the cost of increased inter-annual variability of this performance. The current allocation of fishing effort between the sub-components of the fishery achieves a compromise between performance and risk. With likely changes in economic conditions, maintaining current fishing capacity and effort allocation would achieve the highest economic yield, but for a similar level of performance this would come with higher risk than were a reduced fleet to focus more on the relatively stable tiger-prawn component of the fishery. 


\section{Material and Methods}

\subsection{Case study: the Northern Prawn Fishery}

The Northern Prawn Fishery (NPF), which is located off Australia's northern coast (figure 1), is a multi-species trawl fishery based on several tropical prawn species. It is one of Australia's most valuable federally managed commercial fisheries, and has regularly returned a positive profit (Rose and Kompas, 2004) since its establishment in the late 1960s. However, in recent years the fishery has experienced a decline in value as a result of the increased supply of aquaculture-farmed prawns to both domestic and international markets, strong Australian currency and increasing fuel prices (Punt et al., 2011).

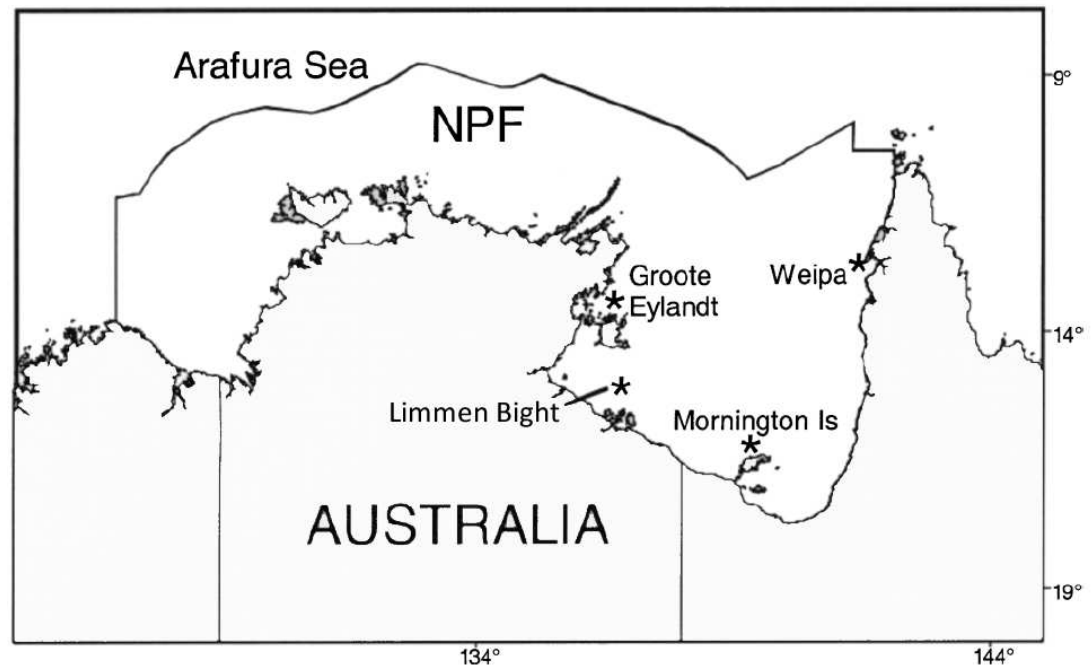

Figure 1: Map of northern Australia showing the extent of the Northern Prawn Fishery (Milton, 2001).

The NPF is currently managed using input controls in the form of limited entry, gear restrictions, as well as time and spatial closures. Management of the fishery has been supported by the development and application of a full Management Strategy Evaluation (MSE) approach (Dichmont et al., 2006, 2008, Venables et al., 2009). Following several industry and government funded buy-back schemes, the NPF now comprises 52 vessels, which is believed to be the number required to achieve Maximum Economic Yield (MEY) in the fishery (Barwick, 
2011). By comparison, more than 120 vessels operated in the fishery a decade ago, and over 300 vessels in the 1970s and 1980s.

The NPF operates over two 'seasons' spanning the period April to November with a midseason closure of variable length from June to August. Seasonal closures are in place to protect small prawns (closure from December to March), as well as spawning individuals (mid-season closure) (AFMA and CSIRO, 2012). The fishery consists of two main sub-fisheries that are (to a large degree) spatially and temporally separate ${ }^{1}$. The banana prawn sub-fishery is a single-species fishery targeting the white banana prawn (Penaeus merguiensis), while the tiger prawn sub-fishery is a mixed species fishery targeting grooved and brown tiger prawns (Penaeus semisulcatus and Penaeus esculentus, respectively), as well as blue endeavour prawns (Metapenaeus endeavouri) which are caught as by-product (Woodhams et al., 2011). Two different fishing strategies can be identified within the tiger prawn sub-fishery, one associated with catching grooved tiger prawns (called the grooved tiger prawn fishing strategy) and the other associated with catching brown tiger prawns (called the brown tiger prawn fishing strategy). White banana prawn stocks are strongly influenced by weather patterns, seasons of higher seasonal catches generally following higher than average rainfall during the preceding summer (Vance et al., 1985). The variability of white banana prawn stocks makes it difficult to set catch or effort limits in a way that protects spawning stocks but also allows operators to profit from years in which prawns are abundant (Buckworth et al., 2013). Tiger prawn stocks are more stable and predictable and these species are generally more dispersed relative to white banana prawns. Consequently, even though the same vessels are used in both sub-fisheries, the fishing gears and techniques differ. The banana prawn sub-fishery operates mostly during the first season. However, if banana prawns are still available in large enough numbers, some ves-

\footnotetext{
${ }^{1}$ A third sub-fishery exists in the Joseph Bonaparte Gulf in the far western part of the fishery based on red-leg banana prawns (Fenneropenaeus indicus). This sub-fishery is exploited by a relatively small number of vessels as it occurs at the same time as the (more valuable) tiger prawn sub-fishery, and is not included in the subsequent analysis.
} 
sels will continue to target them during the second season. The fleet then switches during the second season to the tiger prawn sub-fishery, for which catches per unit effort are lower than for white banana prawns, but less variable.

\subsection{Bio-economic model}

To date, bio-economic analysis of the fishery has been largely focused on the more predictable component of the fishery, namely the tiger prawn sub-fishery (Dichmont et al., 2008, 2010, Punt et al., 2011). The bio-economic model developed here synthesizes, in a single model, previous modelling works by Dichmont et al. (2003, 2008) and Punt et al. $(2010,2011)$ on the NPF, and extends it by integrating the more variable banana prawn resource. The model is based on recent developments in mixed fisheries bio-economic modelling (Gourguet et al., 2013). Our model captures the major components and interactions that characterise the NPF, as described in section 1 and detailed in figure 2.

Population dynamics of tiger and blue endeavour prawns are based on a multi-species weekly time-step, sex-structured population model with Ricker stock-recruitment relationship and environmental uncertainties. The population dynamics model allows for week-specificity in recruitment, spawning, availability and fishing mortality. However, white banana prawns

are represented without explicit density-dependence mechanisms, due to highly variable recruitment and absence of a defined stock-recruitment relationship.

The bio-economic analysis is based on the sake of satisfying trade-offs between expectation and variability of profitability of the entire NPF. By profitability is meant net present value (NPV) of profits, in line with capital theory and optimal control approach (Clark and Munro, 1975). A mean-variance analysis is used to examine the trade-offs.

\subsubsection{Tiger and endeavour prawns: multi-species, stochastic and dynamic models}

The population dynamics of grooved and brown tiger prawns (species $s=1$ and 2, respectively) and blue endeavour prawns $(s=3)$ are based on a sex- and size-structured model relying 


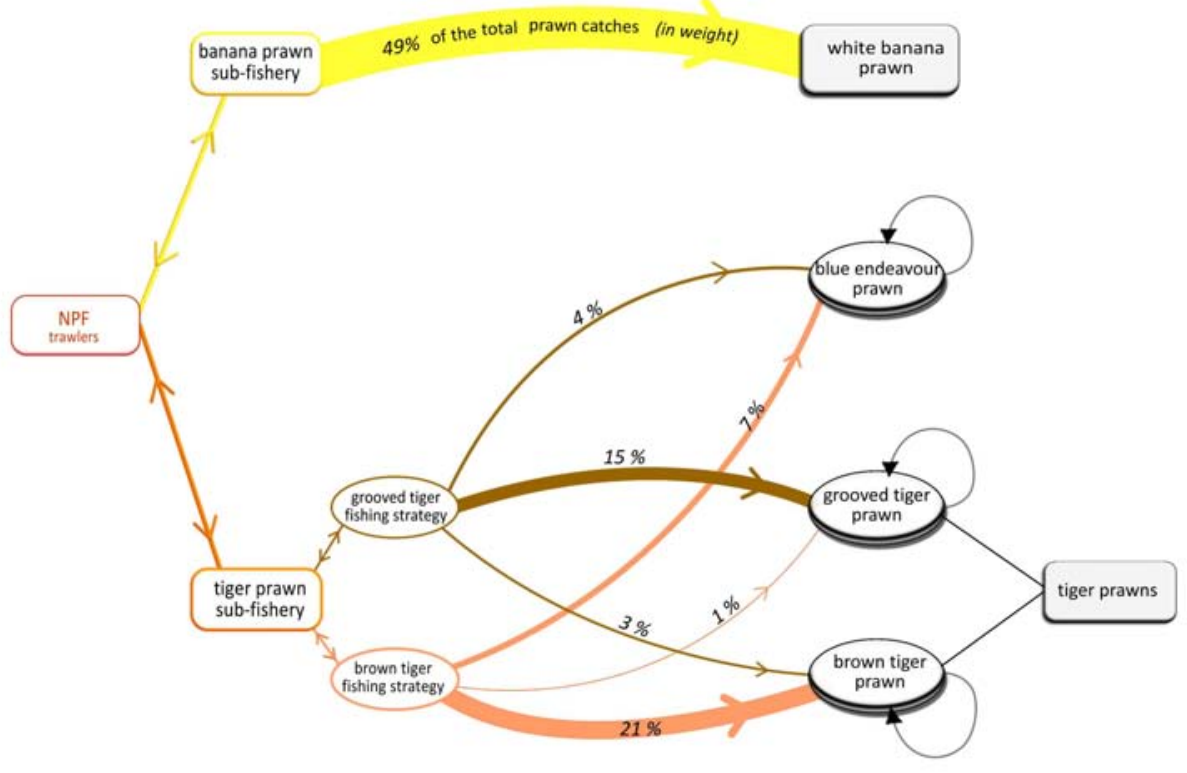

Figure 2: Stylized representation of the Northern Prawn Fishery used as a basis to develop the bioeconomic model. The width of the arrows between the three fishing strategies and various prawns are proportional to the proportion of the catch by species and by fishing strategy compared to the total catch of the fishery in 2010. The three fishing strategies correspond to the two tiger prawn fishing strategies (i.e. the grooved and brown tiger prawn fishing strategies) and the banana prawn sub-fishery. Both tiger prawn fishing strategies result in by-catch of the other tiger prawn species as well as endeavour prawn species.

on a weekly time-step as presented in Punt et al. (2010) and summarized by equation (1):

$$
\vec{N}_{s}(t+1)=\mathrm{g}_{s}\left(t, \vec{N}_{s}(t), \vec{F}_{s}(t)\right), \quad s=1,2,3 .
$$

where $t$ corresponds to one time step, i.e. one week. $\vec{N}_{s}(t)$ is the matrix of abundance $N_{s, x, l}(t)$ of prawns of species $s$ of $\operatorname{sex} x$ (with $x=0^{\pi}$ for male and $q$ for female) in size-class $l$ alive at the start of time $t$. Grooved and brown tiger prawns are represented by 1-mm size-classes between lengths of 15 to $55 \mathrm{~mm}$, while blue endeavour prawns are modelled as a single aggregated length class. $\vec{F}_{s}(t)$ is the matrix of fishing mortality $F_{s, l}(t)$ of animals of species $s$ and size-class $l$ at time $t$. Details on fishing mortality are given in AppendixA.1. The dynamic function $\mathrm{g}_{s}$ accounts for species recruitment and mortality mechanisms of species $s$ as detailed in Punt et al. (2010). Recruits in the fishery for species $s=1,2,3$ during a 'biological' year 
are assumed to be related to the spawning stock size index of species $s$ for the previous year, according to a Ricker stock-recruitment relationship fitted assuming temporally correlated environmental variability and down-weighting recruitments, as described in Punt et al. (2010) and Punt et al. (2011).

\subsubsection{White banana prawn: an uncertain resource}

Abundance of white banana prawns (species $s=4$ ) appears to be more heavily influenced by the environment than by fishing pressure (Die and Ellis, 1999, Venables et al., 2011) and its year to year availability is highly variable. More specifically, stocks are strongly influenced by weather patterns, generally peaking in years in which there has been high rainfall. It is assumed that spawning stock biomasses of white banana prawns do not influence significantly the stock abundances the following years and that annual environmental influences are independent. Therefore, in the present study, white banana prawn annual biomass is modelled as a uniform i.i.d. random variable:

$$
B_{s}(y(t)) \sim \mathcal{U}\left(B_{s}^{-}, B_{s}^{+}\right), \quad s=4
$$

with $B_{s}(y(t))$ the stochastic biomass of white banana prawn for the year $y(t)^{2}$, and $B_{s}^{-}$and $B_{s}^{+}$ the uniform law bounds, for $s=4$.

\subsubsection{Fishing mortality and catch}

Fishing mortalities $F_{s, l, f}(t)$ due to fishing effort of fishing strategy $f$ (with $f=1$ and 2 for the grooved and brown tiger prawn fishing strategies, respectively; and $f=3$ for the banana prawn sub-fishery) on animals of species $s$ in size-class $l$ during time $t$ are given by:

$$
F_{s, l, f}(t)=u_{s}(t) E_{f}(t), \quad s=1,2,3 \quad \text { and } \quad f=1,2 .
$$

where $E_{f}(t)$ corresponds to the effort of fishing strategy $f$ during time $t$. Fishing mortality functions $u_{s}$ are detailed in AppendixA.1.

\footnotetext{
${ }^{2}$ Year $y(t)$ is a function of week $t$, where weeks are numbered $1, \ldots, 52,53, \ldots, 102,103, \ldots$
} 
Weekly catches $Y_{s, l, f}(t)$ of species $s=1,2,3$ in length-class $l$ by tiger prawn fishing strategy $(f=1,2)$; and annual catches $Y_{s=4, f=3}(y(t))$ of white banana prawns $(s=4)$ by the banana prawn sub-fishery $(f=3)$ for the year $y(t)$ are defined by the system of equations (4):

$$
\begin{cases}Y_{s, l, f}(t)=\sum_{x} v_{s, x, l} N_{s, x, l}(t) F_{s, l, f}(t) \frac{1-\exp \left(-M_{s}-\sum_{f=1,2} F_{s, l, f}(t)\right)}{M_{s}+\sum_{f=1,2} F_{s, l, f}(t)} & s=1,2,3 \quad \text { and } \quad f=1,2 \\ Y_{s, f}(y(t))=q_{s, f} B_{s}(y(t)) E_{f}^{\mathrm{y}}(y(t)) & s=4 \quad \text { and } \quad f=3 .\end{cases}
$$

with $v_{s, x, l}$ the mass of an animal of species $s=1,2,3$ and sex $x$ in size-class $l, M_{s}$ the natural mortality of an animal of species $s$, and $E_{f}^{\mathrm{y}}(y(t))$ the annual effort of fleet $f$ during year $y(t)$.

Sub-indices used in this study are summarized in table 1 where their symbols, values and descriptions are displayed.

Table 1: Symbols, values and descriptions of the sub-indices used in the study.

\begin{tabular}{lll}
\hline Symbols & values & Description \\
\hline \multirow{3}{*}{$s$} & 1 & grooved tiger prawn species \\
& 2 & brown tiger prawn species \\
& 3 & blue endeavour prawn species \\
& 4 & white banana prawn species \\
\hline & 1 to 41 & 1-mm length-class between 15 to $55 \mathrm{~mm}$ \\
\hline & 1 & tiger prawn fishing strategy targeting the grooved tiger prawns \\
& 2 & tiger prawn fishing strategy targeting the brown tiger prawns \\
& 3 & banana prawn sub-fishery which targets white banana prawns \\
\hline
\end{tabular}

\subsubsection{Fishing income and costs}

The annual gross incomes of the tiger prawn fishing strategies $(f=1$ and 2$)$ and banana prawn sub-fishery $(f=3)$ are calculated as described by the set of equation (5):

$$
\begin{cases}\operatorname{Inc}_{f}(y(t))=\sum_{t=52(y(t)-1)+1}^{52 y(t)}\left(\sum_{s=1}^{3} \sum_{l} p_{s, l}(y(t)) Y_{s, l, f}(t)\right), & s=1,2,3 \quad \text { and } \quad f=1,2 \\ \operatorname{Inc}_{f}(y(t))=p_{s}(y(t)) Y_{s, f}(y(t)), & s=4 \quad \text { and } \quad f=3 .\end{cases}
$$

where $p_{s, l}(y(t))$ is the average market price per kilogram for animals of species $s=1,2,3$ in size-class $l$ (related to five market categories for the tiger prawns and corresponding to an 
average price for the blue endeavour prawns, as they are represented through an aggregated length-class) during the year $y(t)$. Grooved and brown tiger prawns are marketed together as 'tiger prawns' under a common size- and time-dependent price, therefore $p_{s, l}(y(t))$ are identical for $s=1$ and $s=2$. The average prices per kilogram of blue endeavour and white banana prawns are denoted $p_{s=3,4}(y(t))$ and are also time-, but not size-dependent.

Variable costs $C_{f}^{v a r}(t)$ for the fishing strategy $f$ during time $t$, and annual fixed costs by vessel $C_{v}^{f i x}$ are detailed in equations (6):

$$
\left\{\begin{array}{l}
C_{f}^{v a r}(t)=c^{L} I n c_{f}(t)+c^{M} \sum_{s=1}^{4} Y_{s, f}(t)+\left(c_{f}^{K}+c_{f}^{F}(y(t))\right) E_{f}(t), \\
C_{v}^{f i x}=W^{v}+(r+d) \psi^{v}
\end{array}\right.
$$

where $c^{L}$ is the share cost of labour (crew are paid a share of the income) and $c^{M}$ is the cost of packaging and gear maintenance (assumed to be proportional to the fishery catch in weight). Unit costs $c_{f}^{K}$ and $c_{f}^{F}(y(t))$ are respectively the cost of repairs and maintenance and the cost of fuel and oil per unit of effort of fishing strategy $f$ during the year $y(t)$. The values of these costs are assumed constant across grooved and brown tiger prawn fishing strategies but differ between tiger and banana prawn sub-fisheries. $W^{v}$ are the annual vessel costs (i.e. those costs that are not related to the level of fishing effort), $r$ is the opportunity cost of capital and is assumed equal to the discount rate, set at $5 \%$ following Punt et al. (2011), $d$ is the economic depreciation rate and $\psi^{v}$ is the average value of capital by vessel ${ }^{3}$.

\footnotetext{
${ }^{3}$ The values of cost parameters $\left(c^{L}, c^{M}, c_{f}^{K}, c_{f}^{F}, W^{v}\right.$ and $\left.\psi^{v}\right)$ are derived from an economic survey of the fishery during 2007-2008 (Perks and Vieira, 2010) and were adjusted for known changes in input prices to provide estimates of the costs in 2009-2010 values. All the underlying cost and price assumptions were discussed with, and validated by industry representatives who were members of the NPF Resource Assessment Group (RAG) which has responsibility for assessing the dynamics and status of NPF species. The group comprises fishery scientists, industry members, fishery economists, and the AFMA manager responsible for the fishery.
} 


\subsubsection{Annual profit and net present value}

The total annual profit $\pi(y(t))$ for the entire NPF for year $y(t)$ is given by:

$$
\pi(y(t))=\sum_{f=1}^{3}\left(I n c_{f}(y(t))-\sum_{t=52(y(t)-1)+1}^{52 y(t)} C_{f}^{v a r}(t)\right)-C_{v}^{f i x} K(y(t)) .
$$

where $K(y(t))$ is the number of vessels involved in the NPF during the year $y(t)$.

The net present value (NPV) of the flow of profits over simulation time is calculated as the aggregated value of discounted annual profits and is given by:

$$
N P V=\sum_{y(t)=0}^{T} \frac{\pi(y(t))}{(1+r)^{y(t)}} .
$$

where $r$ is the discount rate, and $T$ is the terminal year of the simulation.

Details on the estimations of the bio-economic model parameters are given in AppendixB, and further details on population dynamics are given in Gourguet (2013).

\subsection{Effort combinations}

In this paper, the economic performance of the NPF is compared under six effort allocations consisting of different effort combinations between tiger and banana prawn sub-fisheries. The effort combinations are described in terms of proportion of total annual effort allocated to the tiger prawn sub-fishery $(f=1+2)$ and are summarized in table 2 . The annual proportion $\propto_{\text {tig }}(y(t))$ of effort directed towards the tiger prawn sub-fishery is expressed as in equation 9:

$$
\left\{\begin{array}{l}
E^{y}(y(t))=E_{f=1+2}^{\mathrm{y}}(y(t))+E_{f=3}^{\mathrm{y}}(y(t)), \\
\propto_{\mathrm{tig}}(y(t))=\frac{E_{f=1+2}^{\mathrm{y}}(y(t))}{E^{y}(y(t))}
\end{array}\right.
$$

where $E^{y}(y(t))$ is the total annual fishing effort for the entire NPF, $E_{f=1+2}^{\mathrm{y}}(y(t))$ corresponds to the annual effort of tiger prawn sub-fishery, and $E_{f=3}^{\mathrm{y}}(y(t))$ of banana prawn sub-fishery, during the year $y(t)$.

In five of the effort combinations, the annual proportion of total effort allocated to tiger prawns $\propto_{\text {tig }}(y(t))$ is pre-defined. Two 'banana effort combinations' ( $\mathrm{T}_{0}$ and $\mathrm{T}_{10}$ ) consist of setting the annual proportion of tiger prawn effort $\propto_{\text {tig }}$ to $0 \%$ and $10 \%$ of total annual effort. 
Two 'tiger effort combinations' $\left(\mathrm{T}_{90}\right.$ and $\mathrm{T}_{100}$ ) involve allocating $90 \%$ and $100 \%$ of the annual effort to the tiger prawn sub-fishery. A 'balanced' effort combination $\left(\mathrm{T}_{50}\right)$ is also analysed, in which total annual effort is split equally between the two sub-fisheries. Finally, an 'adaptive' effort combination $\left(\mathrm{T}_{\text {adapt }}\right)$, which reflects the current fishing behaviour in the NPF, is studied. Under this combination, the allocation of the total annual fishing effort between tiger and banana prawn fishing depends directly on white banana prawn catch per unit effort $C P U E_{s=4}$ as expressed in equation (10):

$$
\propto_{\mathrm{tig}}(y(t))=a C P U E_{s}(y(t))+b, \quad s=4 .
$$

Details on CPUE are given in AppendixA.2. Parameters $a$ and $b$ are estimated from a linear regression model using historical data from 1994 to $2010^{4}$ which is displayed in figure C.2 in AppendixC. The resulting proportion of total annual effort directed to the tiger prawns ranges between 60 and $76 \%$.

Table 2: Effort combinations (in each row) considered in this study. They differ in the annual effort $E_{f=1+2}^{\mathrm{y}}(y(t))$ allocated to tiger prawn sub-fishery.

\begin{tabular}{lll}
\hline Effort combinations & Description & Tiger prawn sub-fishery annual effort \\
\hline $\mathrm{T}_{0}$ & $\propto_{\text {tig }}=0 \%$. & $E_{1+2}^{\mathrm{y}}(y(t))=0$ \\
$\mathrm{~T}_{10}$ & $\propto_{\text {tig }}=10 \%$. & $E_{1+2}^{\mathrm{y}}(y(t))=0.1 E^{y}(y(t))$ \\
$\mathrm{T}_{50}$ & $\propto_{\text {tig }}=50 \%$. & $E_{1+2}^{\mathrm{y}}(y(t))=0.5 E^{y}(y(t))$ \\
$\mathrm{T}_{\text {adapt }}$ & see equation $(10)$. & 'adaptive' tiger prawn effort \\
$\mathrm{T}_{90}$ & $\propto_{\text {tig }}=90 \%$. & $E_{1+2}^{\mathrm{y}}(y(t))=0.9 E^{y}(y(t))$ \\
$\mathrm{T}_{100}$ & $\propto_{\text {tig }}=100 \%$. & $E_{1+2}^{\mathrm{y}}(y(t))=E^{y}(y(t))$ \\
\hline
\end{tabular}

For each of the six effort combinations, the annual tiger prawn effort is then allocated by week and between grooved and brown fishing strategies as described in AppendixA.3.

\subsection{Fleet sizes}

The total annual effort $E^{y}(y(t))$ for the entire NPF can be expressed as in equation (11):

$$
E^{y}(y(t))=e K(y(t))
$$

\footnotetext{
${ }^{4}$ Only historical data after 1993 are taken into account due to major changes in the fishery structure that occurred in that year (Shotton, 2001).
} 
where $e$ is the annual average effort per vessel (set to the value estimated for 2010: 162 days at sea) and $K(y(t))$ the number of vessels for year $y(t)$.

We assess the effects of changes in fishing capacity, in terms of the number of vessels $K(y(t))$. A status quo fleet size SQ corresponding to an annual number of vessels equal to the one observed in 2010 , i.e. $K(y(t))=52$ vessels, but also increased and decreased fleet sizes are studied, as summarized in table 3.

Table 3: Fleet sizes (in each row). v: vessels.

\begin{tabular}{ll}
\hline Management (fleet sizes) & Description. \\
\hline $\mathrm{SQ}$ & $K(y(t))=52 \mathrm{v}$. \\
$\mathrm{K}^{+}$ & $K(y(t))=78 \mathrm{v}$. \\
$\mathrm{K}^{-}$ & $K(y(t))=26 \mathrm{v}$. \\
\hline
\end{tabular}

\subsection{Economic scenarios}

The key economic outputs from the bio-economic model are the annual profits for the entire NPF and the associated net present value, all of which are sensitive to assumptions about the values of biological and economic parameters. Sensitivity to economic parameters is explored through the analysis of scenarios incorporating different assumptions about changes in fuel and prawn prices. All other economic parameters are assumed to remain constant over the simulation period. We report results for only two economic scenarios ${ }^{5}$, these being a 'base case' scenario (BC) and a 'likely' scenario (L) detailed in table 4.

Table 4: Economic scenarios (in each row) considered in this study.

\begin{tabular}{ll}
\hline Scenarios & Description \\
\hline $\mathrm{BC}$ & Base case scenario: constant prawn and fuel prices \\
$\mathrm{L}$ & Likely scenario: prawn prices decrease by 3\% per year \\
& and fuel price increases by 5\% per year \\
\hline
\end{tabular}

\footnotetext{
${ }^{5}$ We tested different combination of scenarios including increase and decrease of prawn and fuel prices. For the sake of clarity and synthesis, only the results relating to a status quo and a likely scenario, which involve two extremes of the scenario combinations tested, are considered.
} 
The $\mathrm{BC}$ scenario assumes that prawn and fuel prices remain constant at their estimated 2010 levels over the simulation period. Variable and fixed costs are set to the average values estimated for the 2010-2012 period. The likely scenario represents a possible evolution over the simulation period of key economic parameters for this fishery (based on historical trends). Except for banana prawn, the main market for NPF prawns is Asia ${ }^{6}$ (especially Japan), and the price received is largely dependent on the Yen-AU\$ exchange rate and the total supplies to this market (Punt et al., 2010). Therefore prawn prices are assumed to be independent of the landings in our model. The likely economic scenario assumes a progressive decrease in prawn prices, by $3 \%$ annually, based on historical trends, and fuel price is assumed to follow a progressive increase of $5 \%$ per year. The later assumption is supported by a linear model adjusted to the historical data given in figure C.1 in the AppendixC.

The economic performance of the fishery for the six effort combinations (c.f. section 2.3), the three fleet sizes (c.f. section 2.4) and under the two economic scenarios (c.f. section 2.5) is analysed accounting for the stochastic nature of the model (i.e. environmental variabilities applied to annual recruitments of tiger and blue endeavour prawns and to white banana prawn annual biomasses). For every combination of effort allocation, fleet sizes and economic scenarios, 1000 trajectories are simulated over a 10 year period from 2010. Each trajectory represents a possible state of nature for each year of the simulation, $\omega()=.\left(\omega_{1}(),. \omega_{2}(),. \omega_{3}(),. \omega_{4}().\right)$; which stands for the set of annual recruitments of tiger and blue endeavour prawns as detailed in Punt et al. (2011) and annual biomasses of white banana prawns as in equation (2). The different $\omega_{i}($.$) are assumed to be independent by species. Each combination of strategies and$ scenarios is simulated with the same set of $\omega($.$) . The numerical implementations and compu-$ tations of the model have been carried out with the scientific software SCILAB ${ }^{7}$.

\footnotetext{
${ }^{6}$ Until recently the main market for banana prawns was also Asia, however most of banana prawns are now sold in domestic market.

${ }^{7}$ ScILAB is a free software http://WwW.scilab.org/ dedicated to engineering and scientific calculus. It is especially well-suited to deal with dynamic systems and control theory.
} 


\section{Results}

\subsection{Mean performance versus risk trade-off in the status quo}

Figure 3 presents the average annual profit of the fishery versus its standard deviation under a status quo fleet size SQ and with current economic conditions in the fishery (i.e. $\mathrm{BC}$ economic scenario), for the six effort combinations. For each combination, the annual variability of income associated with each of the different species is also displayed using bar charts.

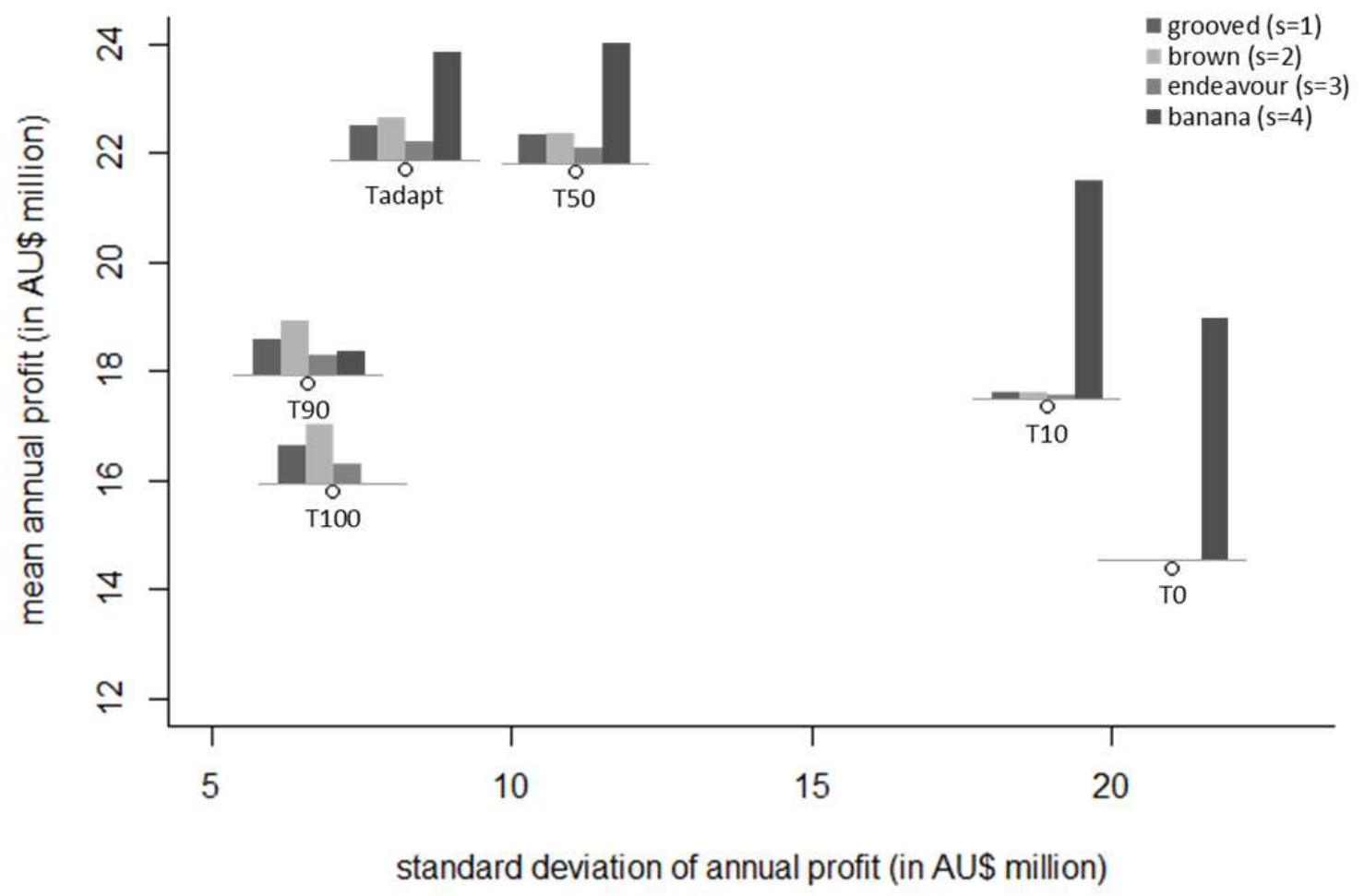

Figure 3: Economic mean-variance analysis for the six effort combinations under a status quo fleet size and a BC economic scenario. For each effort combination, the bar chart represents the standard deviations of the annual incomes estimated from the catches of each of the four species $(s=1,2,3,4)$.

Overall, variability in profits increases with the increase in the proportion of effort that is allocated to the more variable banana prawn component of the fishery. Average annual economic performance increases as the proportion of banana prawn fishing increases, up to a max- 
imum which is reached with mixed effort combinations, while strategies focusing on banana prawn fishing achieve lower levels of average economic performance. Of the effort combinations explored, the $\mathrm{T}_{\text {adapt }}$ one, which mimics the effort combination currently observed in the fishery, provides what appears to be the best compromise between average performance and risk. Strategies specialized on tiger prawn fishing would lead to reduced risk (originating from the two tiger and blue endeavour prawn species), at the cost of reduced average performance. Strategies specialized further on banana prawn fishing would only increase the levels of risk, with no offsetting benefit in terms of average performance.

\subsection{Performance of the NPF with alternative fleet sizes}

The mean-variance performance of the fishery with the three fleet sizes described in section 2.4 and with alternative effort combinations is illustrated in figure 4.

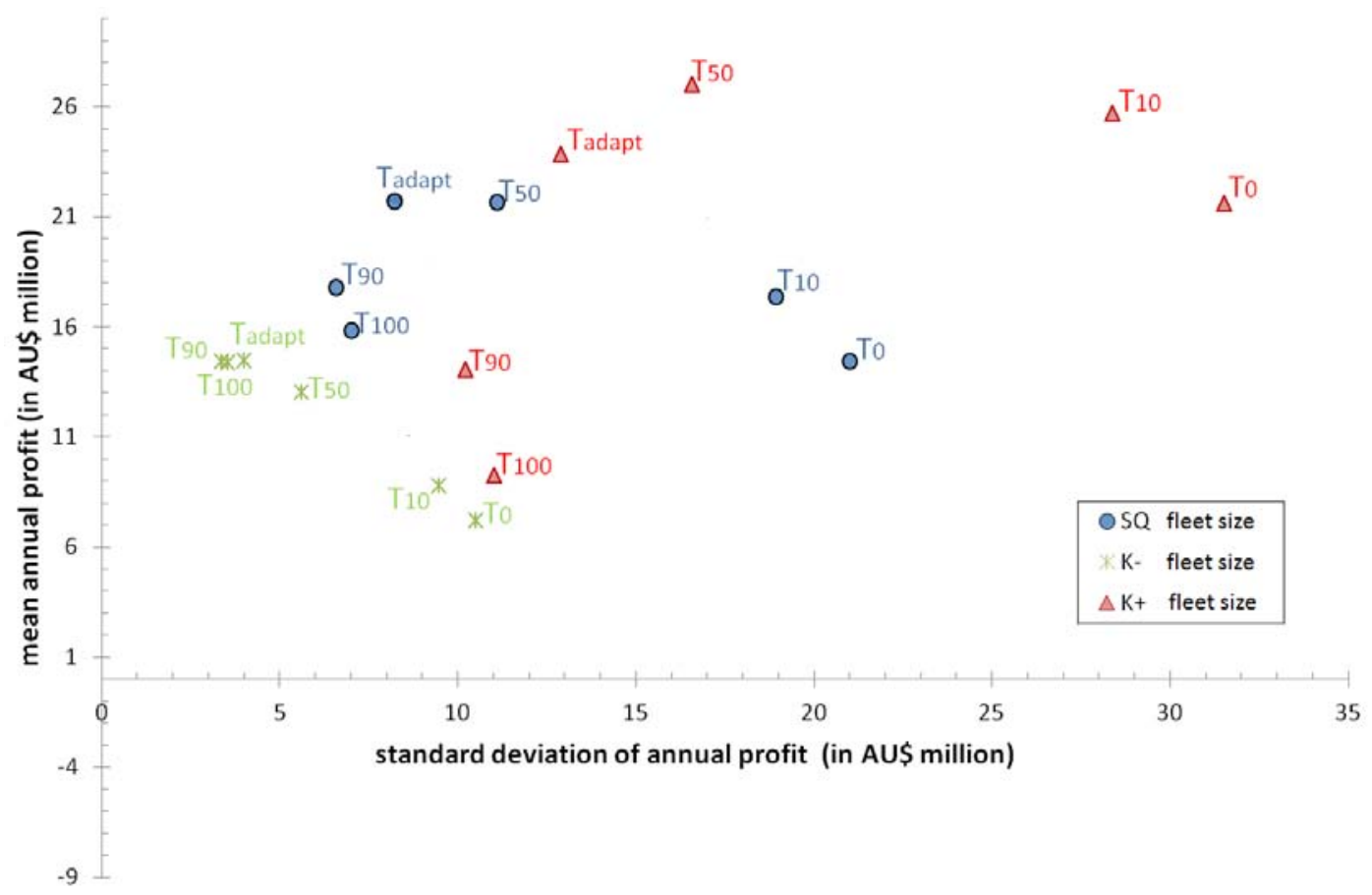

Figure 4: Average annual total profit $\pi(y(t))$ (over the years and the 1000 trajectories simulated) versus the standard deviation associated under a $\mathrm{BC}$ economic scenario. Results are featured by effort combination ( $\mathrm{T}_{\mathrm{adapt}}, \mathrm{T}_{0}, \mathrm{~T}_{10}, \mathrm{~T}_{50}, \mathrm{~T}_{90}$ and $\left.\mathrm{T}_{100}\right)$ with different fleet sizes. The blue circles correspond to a status quo fleet size $\mathrm{SQ}$, the red triangles to an increase in the number of vessels $\mathrm{K}^{+}$and the green crosses to a decrease in the number of vessels $\mathrm{K}^{-}$. 
Comparisons across alternative fleet sizes show that a larger fleet would achieve higher average economic performance with mixed effort combinations including 'adaptive' $\left(\mathrm{T}_{\text {adapt }}\right)$, 'balanced' $\left(\mathrm{T}_{50}\right)$ and 'banana specialisation' $\left(\mathrm{T}_{10}\right)$. However, such average performance would entail much larger levels of variability in economic performance. Inversely, reducing the size of the fleet leads to a reduction of this variability, but is associated with lower mean economic performance levels.

Table 5 presents the mean (among the 1000 trajectories) net present value of fleet profits (NPV) associated with the six effort combinations for each of the three fleet sizes studied. The standard deviation of these NPV are displayed in parentheses.

Table 5: Predicted mean net present value of fleet profits (NPV) achieved by the fishery under a BC economic scenario, associated with the different effort combinations (rows) for each of three alternative fleet sizes (columns). Their standard deviations are displayed in parenthesis. Means and standard deviations are expressed in AU\$ million.

\begin{tabular}{|c|c|c|c|c|}
\hline & Strategies & $\mathrm{K}^{-}$ & SQ & $\mathrm{K}^{+}$ \\
\hline \multirow{6}{*}{ 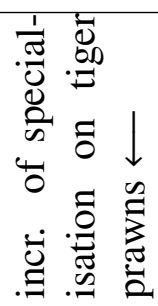 } & $\mathrm{T}_{0}$ & $58.38(28.07)$ & $116.76(56.13)$ & $175.13(84.2)$ \\
\hline & $\mathrm{T}_{10}$ & $71.03(25.36)$ & $140.35(50.71)$ & $208.02(76.05)$ \\
\hline & $\mathrm{T}_{50}$ & 105.31( & 175.89 & 220.4 \\
\hline & $\mathrm{T}_{\text {adapt }}$ & $117.38(14.85)$ & $177.02(29.41)$ & $196.6(43.64)$ \\
\hline & $\mathrm{T}_{90}$ & 117.15 (15.82) & $146.84(28.66)$ & $120.09(39.02)$ \\
\hline & $\mathrm{T}_{100}$ & $117.1(17.11)$ & $131.66(30.56)$ & $82.61(41.01)$ \\
\hline
\end{tabular}

As expected from figure 4, the strategy that increases fleet size allows higher levels of economic yield to be achieved for effort combinations that include banana prawn fishing as a significant component of the overall activity of the fleet (the $\mathrm{T}_{50}$ effort combination achieving the highest yield). This is because the greater fishing capacity allows fishers to make the most of the peak abundance years in banana prawns. However, this is associated with a high level of inter-annual variability in economic yield. As the capacity of the fleet decreases, the ability to capture the full benefits of high abundance years for banana prawns is reduced, and strategies that achieve greater yield (among a reduced fleet size) involve allocating more effort towards the tiger prawns, with reduced levels of economic variability. 


\subsection{Mean-variance analyses under a likely economic scenario}

To explore the sensitivity of our results to potential economic changes to the fishery, figure 5 displays the mean-variance analyses of the fishery with three alternative fleet sizes, and six effort combinations, under a likely (L) economic scenario.

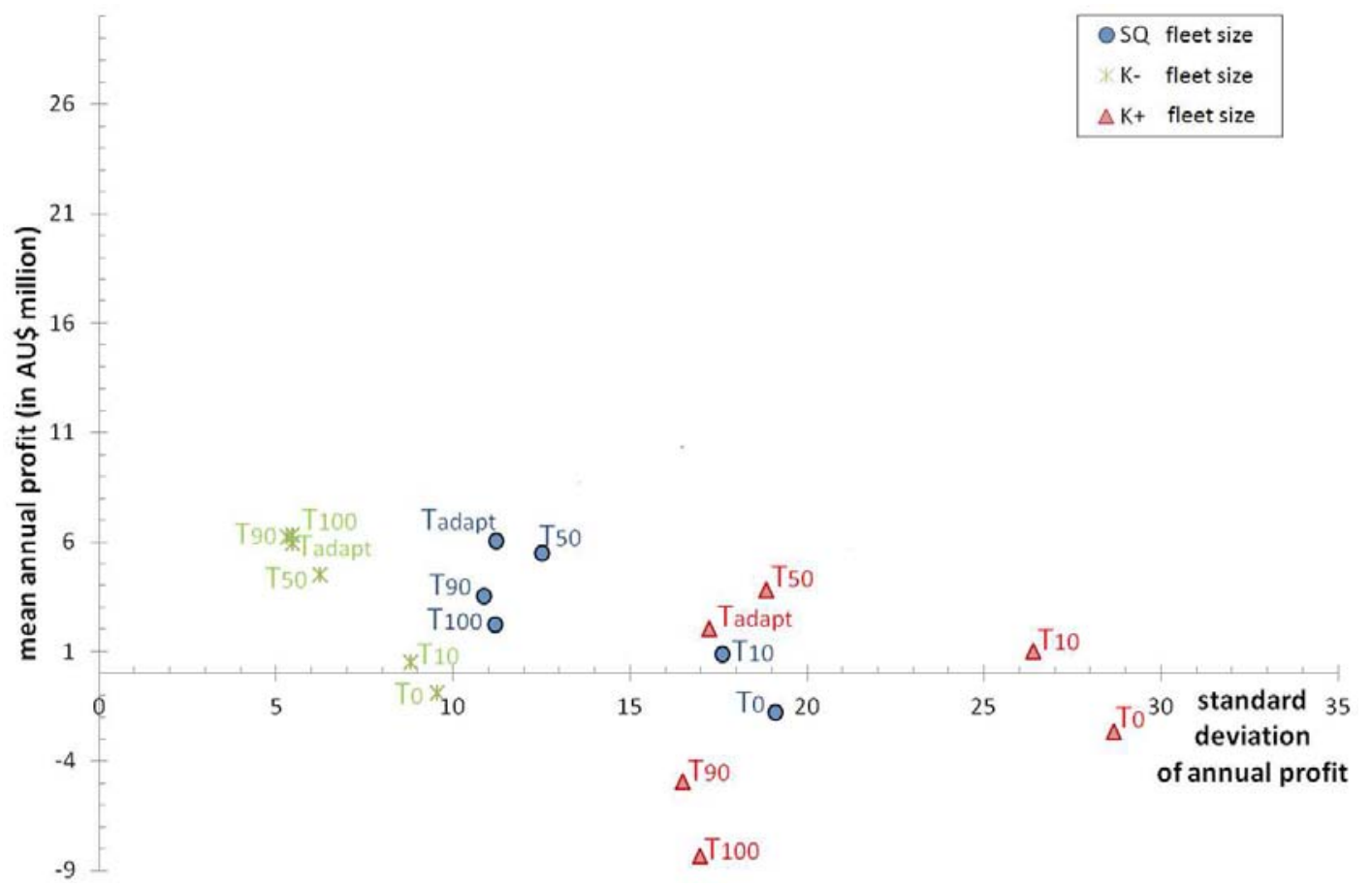

Figure 5: Average annual total profit $\pi(y(t))$ (over the years and the 1000 trajectories simulated) versus the standard deviation associated under a $\mathrm{L}$ economic scenario. Results are featured by effort combination ( $\mathrm{T}_{\text {adapt }}, \mathrm{T}_{0}, \mathrm{~T}_{10}, \mathrm{~T}_{50}, \mathrm{~T}_{90}$ and $\left.\mathrm{T}_{100}\right)$ with different fleet sizes. The blue circles correspond to a status quo fleet size $\mathrm{SQ}$, the red triangles to an increase in the number of vessels $\mathrm{K}^{+}$and the green crosses to a decrease in the number of vessels $\mathrm{K}^{-}$.

Figure 5 shows that under a likely economic scenario, it will not be possible to maintain the current levels of economic yield. Given current fleet size, maintaining current effort allocation would still result in the highest level of average economic yield. However, effort combinations which have similar economic yield, but lower risk are achievable for reduced fleet size.

As illustrated in table 6, the fleet-wide economic yield measured in terms of total net present value over the simulation horizon is highest with the current fleet size. Reducing the number of vessels, and focusing the effort on the tiger-prawn sub-component of the fishery 
Table 6: Predicted mean net present value of fleet profits (NPV) achieved by the fishery under a L economic scenario, associated with the different effort combinations (rows) for each of three alternative fleet sizes (columns). Their standard deviations are displayed in parenthesis. Means and standard deviations are expressed in AU\$ million.

\begin{tabular}{|c|c|c|c|c|}
\hline & Strategies & $\mathrm{K}^{-}$ & SQ & $\mathrm{K}^{+}$ \\
\hline \multirow{3}{*}{ 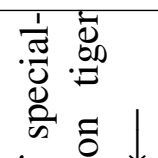 } & $\mathrm{T}_{0}$ & $-2.53(23.58)$ & - $5.07(47.16)$ & - $7.6(70.74)$ \\
\hline & $\mathrm{T}_{10}$ & $8.92(21.29)$ & $16.44(42.58)$ & $22.61(63.87)$ \\
\hline & $\mathrm{T}_{50}$ & $41.36(13.94)$ & $54.24(27.4)$ & $45.71(40.48)$ \\
\hline \multirow{3}{*}{ 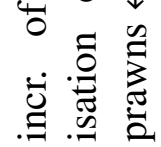 } & $\mathrm{T}_{\text {adapt }}$ & $53.32(12.27)$ & $\mathbf{5 9 . 3}(24.27)$ & $32.36(36.02)$ \\
\hline & $\mathrm{T}_{90}$ & $55.54(13.1)$ & $39.39(23.73)$ & $-23.16(32.34)$ \\
\hline & $\mathrm{T}_{100}$ & $\mathbf{5 6 . 6 1}(14.17)$ & $29.17(25.32)$ & $-50.6(34)$ \\
\hline
\end{tabular}

would entail a modest reduction in the overall yield, but a significant reduction in inter-annual yield variability. A reduced fleet size limits the fleet's ability to gain from the years of high banana prawn abundance, hence the fleet's effort is best targeted at the less variable tiger prawn component of the fishery.

\section{Discussion}

The bio-economic model of the NPF presented in this article is based on the synthesis of a complex set of models developed in support of the Management Strategy Evaluation (MSE) approach to managing this fishery (Dichmont et al., 2006, 2008, Venables et al., 2009). The model, presented here, allows for the explicit representation of both the tiger and the banana prawn sub-fisheries (which are not usually modelled together) and it includes a representation of seasonal allocation of fishing effort, as advocated by Anderson and Seijo (2010). While many features of the original models have been simplified, key aspects of model structure have been maintained where these were considered crucial to the understanding of the bioeconomic system under study.

\subsection{Implication of economic risk when managing a mixed fishery}

The analysis illustrates an important aspect of managing mixed fisheries under the objective of maximising the net present value of profits, as usually proposed in optimal control or 
capital theory approach for fisheries (Clark and Munro, 1975), where fish stocks are taken as natural capital assets. Given the biological variability of some of the target resources in a mixed fishery, increased average profits may be associated with increased inter-annual variability in these profits, which may be perceived as a negative outcome by the industry. This is in line with results encountered in the finance literature (Fishburn, 1977, Ludvigson and Ng, 2007, Rossi and Timmermann, 2010, Jiang and Lee, 2013), where the higher (lower) the returns aimed at, the higher (lower) the associated risk. More specifically, this study illustrates the trade-off between risk and average returns associated with the allocation of fishing effort across species with different levels of biological variability. It also illustrates the trade-off in terms of managing the capacity of the fleet, between being able to take higher catches in years of high banana prawn abundance, but having excess capacity in the low-abundance years; or having a fishing capacity tailored towards the low banana prawn abundance years, with a risk of missing out on some of the potential catch in the high abundance years.

Risk aversion of the industry may lead to management options with lower levels of performance, but reduced economic risk, being preferred. Risk aversion of key stakeholders (fishers, industry, and more broadly, society) should therefore be included in the evaluation of management strategies. As Mistiaen and Strand (2000) pointed out, it is widely agreed that fisher's risk preference is a major determinant of their responses to various changes in fishing stock, market, and weather conditions. Therefore, it is important to integrate fisher's risk preference in modelling and to analyse their decision-making behaviour (Nguyen and Leung, 2009).

The NPF operates under a strong co-management structure, with most of the industry incorporated into a single company which is represented in the management decision process. Moreover industry is involved in setting the number of vessels to achieve MEY. Management and industry objectives can therefore be considered to be relatively aligned (Pascoe et al., 2009). Simulation results show that the total economic yield could actually be increased with a larger number of vessels in the fleet (than the actual 52 vessels), provided the fleet allocated 
half of its effort to the banana prawn sub-fishery (the $\mathrm{T}_{50}$ combination). However, a strategy of increased fleet size would come at the cost of higher economic risk. Results of this study highlight a risk trade-off associated with the $\mathrm{T}_{\text {adapt }}$ effort combination. With a status quo fleet size, this effort combination leads to maximum average annual yield and intermediate levels of inter-annual variability in yield. This scenario, which is based on the historical pattern of effort allocation in the fishery, may thus reflect the degree to which the decision makers (industry together with government managers) are willing to trade of average profit against variability.

While the results obtained are specific to the case study considered in this analysis, the methods proposed would apply to any mixed fishery where information allows calibration of a dynamic bio-economic model of fishing across a range of species presenting different levels of natural variability. It is likely that most of the mixed fisheries in the world would be subject to similar trade-offs between average economic performance and variability of this performance from year to year. If this is the case, we argue that the question of variability in returns of a fishery should also be considered when discussing the identification of management strategies aimed at MEY. This would raise the question of the degree of risk aversion of key stakeholders, including industry, the fishers, and more broadly, society.

\subsection{Likely economic scenario and possible adaptation options}

Analyses of economic performance of the fishery under different economic scenarios illustrate the importance of sensitivity analyses to key economic parameters in bio-economic assessments. Whereas it is difficult to predict the future evolution of prices and costs as they are influenced principally by external drivers, scenarios and projections - based on the best available knowledge of these drivers - show that the fishery is likely to encounter economic challenges, with higher fuel and lower product prices resulting in average annual profit levels expected to be low compared to the current situation (and even negative in some periods). Increased fleet size, given the costs per vessel, would in this case fail to improve fishery performance, in terms of mean annual profits, net present values and economic risk. However, 
reducing fleet size below its historical level would induce a reduction in economic risk, while involving only a limited loss in economic yield. Furthermore, increase in fuel prices would lead to a relatively more important increase in variable costs for the banana prawn sub-fishery, compared to the tiger prawn sub-fishery, as the banana prawn sub-fishery uses a greater amount of fuel per effort unit. This, and the limited capacity of the fleet to take advantage of the good years of banana prawn abundance, would lead to favour tiger prawn effort specialisations.

\subsection{Perspectives}

Fisheries management increasingly acknowledges that fish population dynamics are complex and influenced by factors that are often poorly understood. This is the case with the white banana prawn dynamics. It may be that the conclusions of our analysis would change if the patterns of variability in abundance of banana prawns changed, due for example to changes in the environmental drivers which determine its year-to-year fluctuations in abundance. In particular, rainfall and sea level rise have been identified by Hobday et al. (2008) as key impacts of climate change in the NPF region, which may have an impact on the dynamics of the different species targeted by the NPF, notably on white banana prawn abundance. Climate change projections for rainfall are highly uncertain; rainfall is projected to decrease across parts of northern Australia, with some areas showing a slight increase which may have a positive impact on white banana prawn catches (Hobday et al., 2008). Climate change may also have an impact on seagrass beds and mangrove forests, which are important nursery grounds for tiger prawns and banana prawns, respectively (Sands, 2011). Coupling the bio-economic model presented in this paper with projections derived from models relating climate change to the environmental drivers of prawn abundance could therefore allow a more informed evaluation of the future trade-offs between mean performance and economic risk in this fishery.

Finally, while our analysis has focused exclusively on the bio-economic trade-offs associated with species with commercial value, another key dimension of mixed fisheries which may also need to be considered is the impact of effort combinations on by-catch species of 
low commercial value, as well as on threatened, endangered and protected species and on habitats (Woodhams et al., 2011). Different levels of fishing capacity and alternative effort combinations, impacting differently the surrounding ecosystem, will potentially lead to different outcomes in terms of the ecological impacts of fishing. This will be the focus of further research using the bio-economic model presented in this article.

\section{Acknowledgement}

This work was carried out as part of a co-tutelle $\mathrm{PhD}$ project jointly funded by Ifremer and the joint CSIRO/UTAS PhD Program in Quantitative Marine Sciences. Additional support was provided by the French Research Agency ANR as part of the Adhoc project, as well as by the Australian Fisheries Research and Development Corporation (FRDC). We are extremely grateful to the CSIRO researchers for providing access to the models and data relating to the NPF, and for their guidance in the analyses presented in the paper. We also thank three anonymous reviewers for their helpful comments on an earlier version of the manuscript

\section{References}

ABARES, 2010. Australian commodity statistics 2010. Tech. rep., Canberra.

AFMA, CSIRO, June 2012. Harvest Strategy for the Northern Prawn Fishery under input controls. Tech. rep., Canberra.

Anderson, L., Seijo, J., 2010. Bioeconomics of fisheries management. Wiley-Blackwell.

Barwick, M., 2011. Northern Prawn Fishery Data Summary 2010. Tech. rep., NPF Industry Pty Ltd, Australia.

Buckworth, R., Ellis, N., Zhou, S., Pascoe, S., Deng, R., Hill, F., O’Brien, M., 2013. Comparison of TAC and current management for the White Banana Prawn fishery of the Northern Prawn Fishery. Final Report to the Australian Fisheries Management Authority. Tech. rep., CSIRO Marine and Atmospheric Research, Brisbane.

Clark, C., Munro, G., 1975. The economics of fishing and modern capital theory: a simplified approach. Journal of environmental economics and management 2 (2), 92-106. 
Dichmont, C., Deng, A., Punt, A., Ellis, N., Venables, W., Kompas, T., Ye, Y., Zhou, S., Bishop, J., 2008. Beyond biological performance measures in Management Strategy Evaluation: Bringing in economics and the effects of trawling on the benthos. Fisheries Research 94 (3), 238-250.

Dichmont, C., Deng, A., Punt, A., Venables, W., Haddon, M., 2006. Management strategies for short-lived species: The case of Australia's Northern Prawn Fishery: 1. Accounting for multiple species, spatial structure and implementation uncertainty when evaluating risk. Fisheries research 82 (1), 204-220.

Dichmont, C., Pascoe, S., Kompas, T., Punt, A., Deng, A., 2010. On implementing maximum economic yield in commercial fisheries. Proceedings of the National Academy of Sciences 107 (1), 16-21.

Dichmont, C., Punt, A., Deng, A., Dell, Q., Venables, W., 2003. Application of a weekly delay-difference model to commercial catch and effort data for tiger prawns in Australia's Northern Prawn Fishery. Fisheries Research 65 (1-3), 335-350.

Die, D., Ellis, N., 1999. Aggregation dynamics in penaeid fisheries: banana prawns (Penaeus merguiensis) in the Australian Northern Prawn Fishery. Marine and freshwater research 50 (7), 667-675.

Epstein, L., 1985. Decreasing risk aversion and mean-variance analysis. Econometrica: Journal of the Econometric Society, 945-961.

Fishburn, P., 1977. Mean-risk analysis with risk associated with below-target returns. The American Economic Review 67 (2), 116-126.

Francis, R., Shotton, R., 1997. 'Risk' in fisheries management: A review. Canadian Journal of Fisheries and Aquatic Sciences 54, 1699-1715.

Gourguet, S., 2013. Ecological and economic viability for the sustainable management of mixed fisheries. Ph.D. thesis, Université de Bretagne Occidentale and Univeristy of Tasmania.

Gourguet, S., Macher, C., Doyen, L., Thébaud, O., Bertignac, M., Guyader, O., 2013. Managing mixed fisheries for bio-economic viability. Fisheries Research 140, 46-62.

Hilborn, R., Maguire, J., Parma, A., Rosenberg, A., 2001. The precautionary approach and risk management: can they increase the probability of successes in fishery management? Canadian Journal of Fisheries and Aquatic Sciences 58 (1), 99-107.

Hobday, A., Poloczanska, E., Matear, R., et al., August 2008. Implications of climate change for Australian fisheries and aquaculture: a preliminary assessment. Tech. rep., Report to the Department of Climate Change, Canberra, Australia.

Holland, D., Herrera, G., 2009. Uncertainty in the management of fisheries: contradictory implications and a new approach. Marine Resource Economics 24 (3), 289. 
Jiang, X., Lee, B.-S., 2013. The intertemporal risk-return relation: A bivariate model approach. Journal of Financial Markets in press.

Kasperski, S., Holland, D., 2013. Income diversification and risk for fishermen. Proceedings of the National Academy of Sciences 110 (6), 2076-2081.

Ludvigson, S., Ng, S., 2007. The empirical risk-return relation: A factor analysis approach. Journal of Financial Economics 83 (1), 171-222.

Markowitz, H., 1952. Portfolio selection. The Journal of Finance 7 (1), 77-91.

Milton, D., 2001. Assessing the susceptibility to fishing of populations of rare trawl bycatch: sea snakes caught by Australia's Northern Prawn Fishery. Biological Conservation 101 (3), 281-290.

Mistiaen, J., Strand, I., 2000. Location choice of commercial fishermen with heterogeneous risk preferences. American Journal of Agricultural Economics 82 (5), 1184-1190.

Munro, G., 2010. The way forward: Getting the economic theory right - the first steps. In: Proceedings of the Fifteenth Biennial Conference of the International Institute of Fisheries Economics and Trade.

Nguyen, Q., Leung, P., 2009. Do fishermen have different attitudes toward risk? An application of prospect theory to the study of Vietnamese fishermen. Journal of Agricultural and Resource Economics 34 (3), 518.

Pascoe, S., Proctor, W., Wilcox, C., Innes, J., Rochester, W., Dowling, N., 2009. Stakeholder objective preferences in Australian Commonwealth managed fisheries. Marine Policy 33 (5), 750-758.

Perks, C., Vieira, S., 2010. Australian fisheries surveys report 2010, Results for selected fisheries, 2007-08 and 2008-09, Preliminary estimates for 2009-10. Tech. rep., ABARES report prepared for the Fisheries Resources Research Fund, Canberra, December.

Punt, A., Deng, R., Dichmont, C., Kompas, T., Venables, W., Zhou, S., Pascoe, S., Hutton, T., Kenyon, R., van der Velde, T., et al., 2010. Integrating size-structured assessment and bioeconomic management advice in Australia's Northern Prawn Fishery. ICES Journal of Marine Science: Journal du Conseil 67 (8), 1785-1801.

Punt, A., Deng, R., Pascoe, S., Dichmont, C., Zhou, S., Plagányi, É., Hutton, T., Venables, W., Kenyon, R., van der Velde, T., 2011. Calculating optimal effort and catch trajectories for multiple species modelled using a mix of size-structured, delay-difference and biomass dynamics models. Fisheries Research 109, 201-211.

Rose, R., Kompas, T., 2004. Management options for the Australian Northern Prawn Fishery. Australian Bureau of Agricultural and Resource Economics, Commonwealth of Australia, Canberra 47. 
Rossi, A., Timmermann, A., 2010. What is the shape of the risk-return relation? In: AFA 2010 Atlanta Meetings Paper.

Roy, A., 1952. Safety first and the holding of assets. Econometrica: Journal of the Econometric Society, 431-449.

Sanchirico, J., Smith, M., Lipton, D., 2008. An empirical approach to ecosystem-based fishery management. Ecological Economics 64 (3), 586-596.

Sands, A., May 2011. Fisheries and climate change: potential challenges and opportunities for Commonwealth fisheries. Tech. rep., ABARES technical report 11.1, Canberra, Australia.

Sethi, S. A., 2010. Risk management for fisheries. Fish and Fisheries 11 (4), 341-365.

Shotton, R., 2001. Changes in Fleet Capacity and Ownership of Harvesting Rights in Australia's Northern Prawn Fishery. FAO Fisheries Technical Paper 412.

Vance, D., Staples, D., Kerr, J., 1985. Factors affecting year-to-year variation in the catch of banana prawns (Penaeus merguiensis) in the Gulf of Carpentaria, Australia. ICES Journal of Marine Science: Journal du Conseil 42 (1), 83-97.

Venables, B., Hutton, T., Lawrence, E., Rothlisberg, P., Buckworth, R., Hartcher, M., Kenyon, R., 2011. Prediction of common banana prawn potential catch in Australia's Northern Prawn Fishery. Prepared for Australian Fisheries Management Authority. Tech. rep., CSIRO.

Venables, W., Ellis, N., Punt, A., Dichmont, C., Deng, R., 2009. A simulation strategy for fleet dynamics in Australia's Northern Prawn Fishery: effort allocation at two scales. ICES Journal of Marine Science: Journal du Conseil 66 (4), 631-645.

Woodhams, J., Stobutzki, I., Vieira, S., Curtotti, R., (eds), B. G., 2011. Fishery status reports 2010: status of fish stocks and fisheries managed by the Australian government. Tech. rep., Australian Bureau of Agricultural and Resource Economics and Sciences.

\section{Appendix A: Dynamics details of the bio-economic model}

\section{AppendixA.1. Fishing mortality}

Fishing mortalities of species $s=1,2,3$ are given by:

$$
\begin{cases}F_{s, l, f}(t)=A_{s}(t) \operatorname{Sel}_{s, l} q_{s, f} E_{f}(t), & s=1,2 \text { and } f=1,2 \\ F_{3, f}(t)=A_{s}(t) q_{s, f} E_{f}(t), & s=3 \text { and } f=1,2 .\end{cases}
$$

where $A_{s}(t)$ is the relative availability of animals of species $s$ during time $t$ and $E_{f}(t)$ is fishing effort (days at sea) associated with grooved or brown tiger prawn sub-fishery $f=1,2$ at time $t$. Catchability $q_{s, f}$ corresponds to the fishing mortality of species $s$ associated with one unit of fishing effort of fishing strategy $f$ (as in 2010) and is assumed constant over the simulation period. $S e l_{s, l}$ is the selectivity of the fishing gear on animals of species $s$ in size-class $l$ as described in Punt et al. (2010). 
AppendixA.2. CPUE

Annual average banana catch per unit effort (CPUE) are computed from white banana prawn annual biomass $B_{s=4}(y(t))$, as:

$$
C P U E_{s}(y(t))=q_{s, f} B_{s}(y(t)), \quad s=4 \text { and } f=3 .
$$

where $q_{s, f}$ is the catchability of the white banana prawn $(s=4)$ by the banana prawn subfishery $(f=3)$. Estimated values of $q_{s=4, f=3}$ are given in appendix B table D.1.

\section{AppendixA.3. Weekly effort allocation model}

To capture what happens currently in the NPF, the total annual fishing effort is allocated weekly between tiger and banana prawn sub-fisheries, and then between the two tiger prawn species through a simplified, two-steps, effort allocation model.

- Step 1: Weekly tiger prawn sub-fishery effort allocation

An empirical approach is taken to predict the weekly allocation of the tiger prawn subfishery effort for year $y(t)$. Because of the great variability of the various weekly effort patterns of the historical years, using a fixed weekly pattern is not relevant. Due to the influence of the season start dates and annual effort of banana prawn sub-fishery on the tiger prawn weekly effort patterns, the solution to randomly select a year among the historical years 1994 to 2010 was estimated as not optimal for this study. Sensitivity analyses of weekly patterns would indeed be necessary, and would increase the number of simulations to run, increasing significantly the level of complexity of the model. For simplicity, weekly tiger prawn effort are estimated as described in equation A.3

$$
\begin{aligned}
& \min _{E_{f=1+2}^{H i s t}}\left[\sum_{t}\left\|E_{f=1+2}(t)-E_{f=1+2}^{H i s t}(t)\right\|\right] \\
& \left\{\begin{array}{l}
E_{f=1+2}\left(t_{i}^{*}\right)=0 \\
\sum_{t} E_{f=1+2}(t)=E_{f=1+2}^{\mathrm{y}}(y(t))
\end{array}\right.
\end{aligned}
$$

with $t_{i}^{*}$ corresponding to the weeks which are closed to the fishery for management constraints (the pattern of open and closed weeks is set to that which occurred in 2010), and $E_{f=1+2}^{H i s t}$ standing for the weekly historical effort registered for the tiger prawn subfishery.

- Step 2: Grooved and brown tiger prawn fishing strategies effort allocation

The second step of the effort distribution model (arrow (3) in figure A.1) allocates the weekly tiger effort to the grooved and brown tiger prawns. This is achieved using a fixed pattern ${ }^{8} \Upsilon^{\text {grooved }}(t$ modulo 52) of proportion of weekly tiger prawn effort directed towards grooved tiger prawns $(f=1)$ at time ( $t$ modulo 52). The effort by week directed towards

\footnotetext{
${ }^{8}$ The values of $\Upsilon^{\text {grooved }}(t)$ correspond to the predicted proportion of tiger prawn effort directed towards the grooved prawns during week ( $t$ modulo 52) in 2010 derived from the CSIRO operating model.
} 
grooved $(f=1)$ and brown $(f=2)$ tiger prawns is described by equation (A.4):

$$
\left\{\begin{array}{l}
E_{f=1+2}(t)=E_{f=1}(t)+E_{f=2}(t) \\
E_{f=1}(t)=\Upsilon^{\text {grooved }}\left(t \text { modulo 52) } E_{f=1+2}(t) .\right.
\end{array}\right.
$$

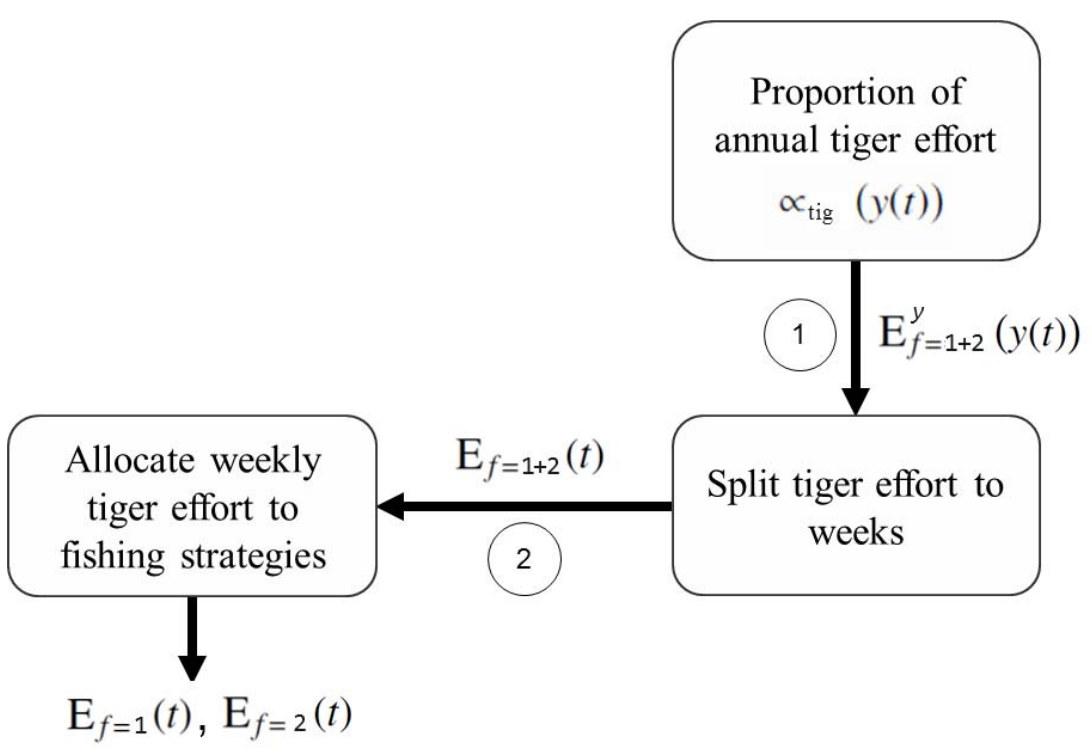

Figure A.1: Flowchart of the algorithm used to determine the weekly effort (days at sea) during year $y(t)$ of grooved and brown tiger prawn fishing strategies $(f=1,2)$, according to the proportion of effort directed to tiger prawn sub-fishery. The variables next to the arrows represent the output from one box and input into another box.

\section{Appendix B: Parameter estimation}

Dichmont et al. (2003) and Punt et al. (2010) describe the approaches used to estimate parameter values for the dynamic population models. The impact of parameter uncertainty was explored in Punt et al. (2010). A non-linear least-squares method was used for the estimation of the parameters $\left(B_{s=4}^{-}, B_{s=4}^{+}\right.$and $\left.q_{s=4, f=3}\right)$ related to white banana prawn by fitting observed data of white banana prawn catches (in weight) and annual banana fishing effort over 17 years, from 1994 to 2010 (c.f. figure C.2 in AppendixC). Base case values of all biological and economic parameters are given in AppendixD.

\section{Appendix C: Statistical analyses}

This appendix displays the outputs of statistical analyses used to calibrate the bio-economic model and scenario projections. Figure C.1 represents the linear regression used for the projection of the fuel prices and figure C.2 the one used for the $\mathrm{T}_{\text {adapt }}$ effort combination described in section 2.3 


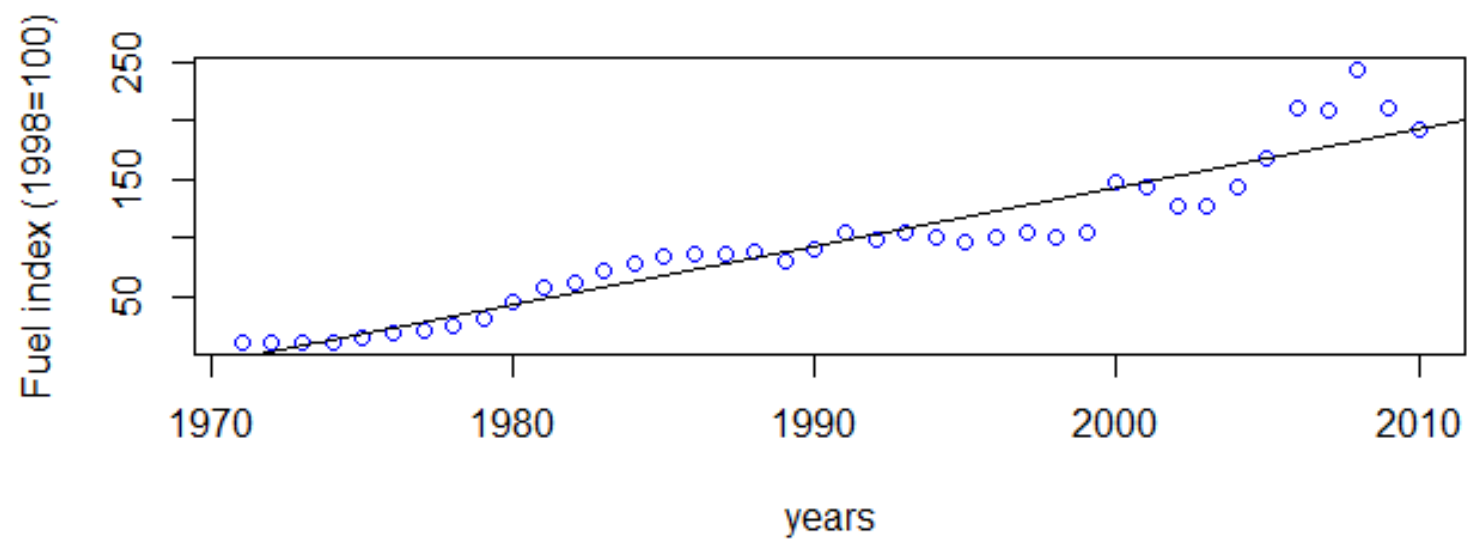

Figure C.1: Linear regression of fuel price index relying on historical data from 1971 to $2010 . R^{2}=$ 0.9033 and Pvalue $=2.2 * 10^{-16}(<0.05$, significant $)$. The slope of the regression line is 4.9831 (meaning an increase of 5\% per year). Data source: ABARES (2010).

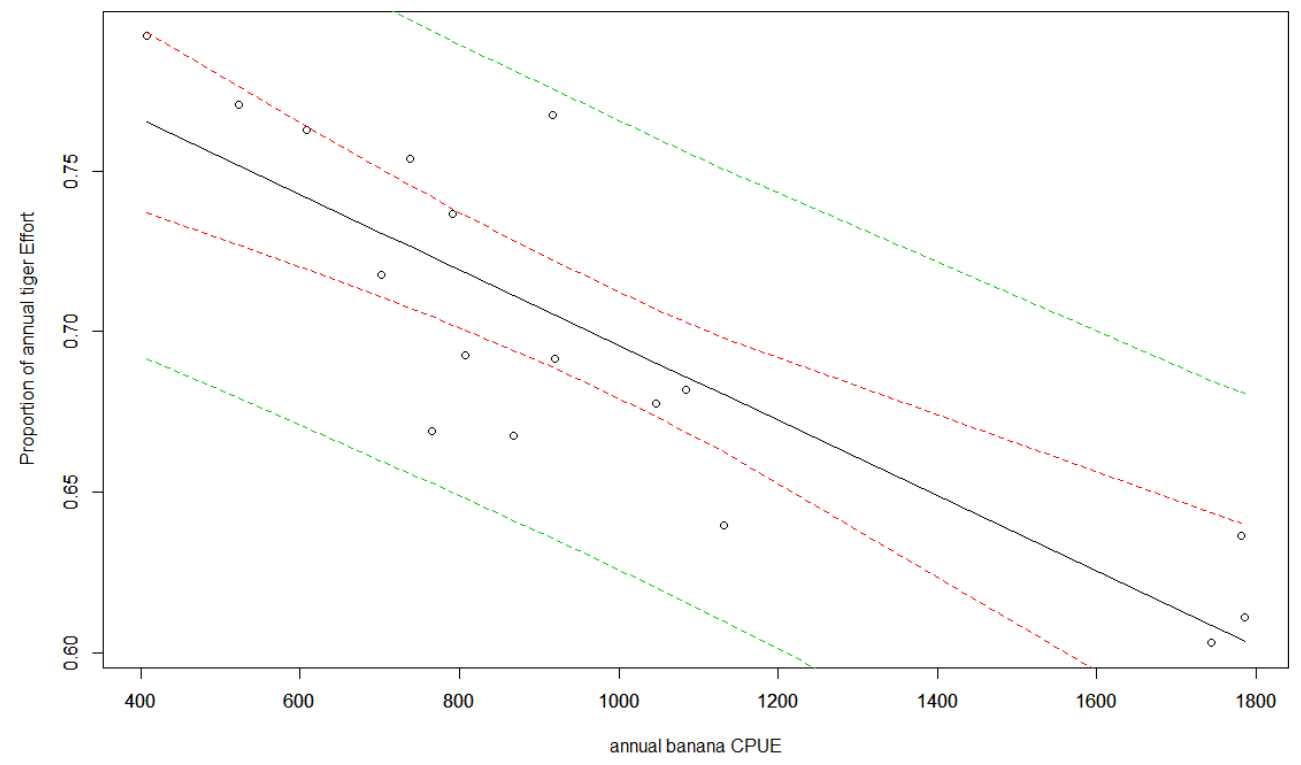

Figure C.2: Linear regression $\left(\propto_{\operatorname{tig}}(y)=a C P U E_{s=4}(y)+b\right)$ between the average annual banana catch per unit effort, $C P U E_{s=4}$ and the annual proportion of tiger prawn sub-fishery effort, $\propto_{\text {tig. }}$. Model relies on historical catches and effort data from 1994 to $2010 . R^{2}=0.7016$ and Pvalue $=1.657 * 10^{-5}\left(<0.05\right.$, significant). $a=-1.172 * 10^{-4}$ and $b=0.813$. 


\section{Appendix D: Bio-economic parameter values}

This appendix displays the values of the biological and economic parameters used to calibrate the bio-economic model presented in section 2. Table D.1 displays the parameters related to the white banana prawn, while table D.2 summarizes the catchabilities parameter values for the grooved and brown tiger and blue endeavour prawns. Tables D.3 and D.4 summarize the values of parameters involved in the profit equation. Table D.5 exhibits the weekly proportion of tiger prawn sub-fishery effort directed towards grooved and brown tiger prawn fishing strategies used to split the tiger prawn sub-fishery effort into grooved and brown tiger prawn fishing strategies as described in section AppendixA.3.

Table D.1: Estimated parameters related to white banana prawn $(s=4$ and $f=3)$.

\begin{tabular}{lccc}
\hline & $B_{s}^{-}$ & $B_{s}^{+}$ & catchability, \\
& (in thousand tonnes) & (in thousand tonnes) & $q_{s, f}$ \\
\hline white banana prawn & 28.72 & 125.8 & 0.0000142 \\
\hline
\end{tabular}

Table D.2: Estimated values of catchabilities $q_{s, f}$ by species $s$ and by tiger prawn fishing strategies $f=1,2$ for a fishing power of the fishery as in 2010 .

\begin{tabular}{lcc}
\hline \multirow{2}{*}{ prawn species } & \multicolumn{2}{c}{ Tiger prawn sub-fishery } \\
\cline { 2 - 3 } & grooved tiger prawn fishing strategy & brown tiger prawn fishing strategy \\
& $f=1$ & $f=2$ \\
\hline grooved tiger & 0.0001219 & 0.0000152 \\
brown tiger & 0.0000111 & 0.0001219 \\
blue endeavour & 0.0001149 & 0.0002839 \\
\hline
\end{tabular}

Table D.3: Prawn prices $p_{s}(2010)$ (AU\$ per kilogramme) by species group and size-class in 2010 .

\begin{tabular}{lcccccc}
\hline Species group & All sizes & $<40 \mathrm{~mm}$ & $40-45 \mathrm{~mm}$ & $45-50 \mathrm{~mm}$ & $50-55 \mathrm{~mm}$ & $>55 \mathrm{~mm}$ \\
\hline tiger, $p_{\text {tig, } l}$ & 19.05 & 15.30 & 19.91 & 20.83 & 27.19 & 26.83 \\
endeavour, $p_{s=3}$ & 9.64 & & & & & \\
banana, $p_{s=4}$ & 9.5 & & & & & \\
\hline
\end{tabular}


Table D.4: Economic parameters.

\begin{tabular}{|c|c|c|}
\hline (a) Variable costs & \multicolumn{2}{|c|}{ fishing strategies } \\
\hline Parameters & tiger $(f=1,2)$ & banana $(f=3)$ \\
\hline Unit Cost of repairs and maintenance, $c_{f}^{K}$ & 332 (AU\$/day) & 529 (AU\$/day) \\
\hline Base unit cost of fuel and grease, $c_{f}^{F}(2010)$ & 1815 (AU\$/day) & 2236 (AU\$/day) \\
\hline Share cost of labor, $c^{L}$ & 0.24 & 0.24 \\
\hline Cost of packaging and gear maintenance, $c^{M}$ & $0.92(\mathrm{AU} \$ / \mathrm{kg})$ & $0.92(\mathrm{AU} \$ / \mathrm{kg})$ \\
\hline \multicolumn{3}{|l|}{ (b) Fixed costs and rates } \\
\hline Parameters & Value & \\
\hline Annual vessel costs, $W^{v}$ & 296,847 (AU\$/vessel) & \\
\hline Opportunity cost of capital, $r$ & 0.05 & \\
\hline Economic depreciation rate, $d$ & 0.037 & \\
\hline Average value of capital, $\psi^{v}$ & 1,135,693 (AU\$/vessel) & \\
\hline \multicolumn{3}{|l|}{ (c) NPF fishery status in 2010} \\
\hline Variable & Value & \\
\hline Number of vessels, $K(2010)$ & 52 & \\
\hline Annual average effort (days/vessel), $e(2010)$ & 162 & \\
\hline
\end{tabular}

Table D.5: Pattern of weekly effort by tiger prawn fishing strategy (i.e. grooved or brown) set to 0 for closed weeks (predicted for the year 2010).

\begin{tabular}{lcc}
\hline & \multicolumn{2}{c}{ Tiger prawn fishing strategies effort pattern } \\
\cline { 2 - 3 } weeks & $\begin{array}{c}\text { proportion directed to } \\
\text { grooved tiger prawn, } \Upsilon^{\text {grooved }}(t)\end{array}$ & $\begin{array}{c}\text { proportion directed to } \\
\text { brown tiger prawn, }\left(1-\Upsilon^{\text {grooved }}(t)\right)\end{array}$ \\
\hline 1 & 0 & 0 \\
2 & 0 & 0 \\
3 & 0 & 0 \\
4 & 0 & 0 \\
5 & 0 & 0 \\
6 & 0 & 0 \\
7 & 0 & 0 \\
8 & 0 & 0 \\
9 & 0 & 0 \\
10 & 0 & 0 \\
11 & 0 & 0 \\
12 & 0 & 0 \\
13 & 0 & 0 \\
14 & 0.55052002 & 0.44947998 \\
15 & 0.44202646 & 0.55797354 \\
16 & 0.54208048 & 0.45791952 \\
\hline
\end{tabular}




\begin{tabular}{|c|c|c|}
\hline weeks & $\begin{array}{l}\text { proportion of effort towards } \\
\text { grooved tiger prawn, } \Upsilon^{\text {grooved }}(t)\end{array}$ & $\begin{array}{c}\text { proportion of effort towards } \\
\text { brown tiger prawn, }\left(1-\Upsilon^{\text {grooved }}(t)\right)\end{array}$ \\
\hline 17 & 0.37494679 & 0.62505321 \\
\hline 18 & 0.48131314 & 0.51868686 \\
\hline 19 & 0.47449422 & 0.52550578 \\
\hline 20 & 0.50102323 & 0.49897677 \\
\hline 21 & 0.4236849 & 0.5763151 \\
\hline 22 & 0.46343995 & 0.53656005 \\
\hline 23 & 0.46358818 & 0.53641182 \\
\hline 24 & 0 & 0 \\
\hline 25 & 0 & 0 \\
\hline 26 & 0 & 0 \\
\hline 27 & 0 & 0 \\
\hline 28 & 0 & 0 \\
\hline 29 & 0 & 0 \\
\hline 30 & 0 & 0 \\
\hline 31 & 0.14321391 & 0.85678609 \\
\hline 32 & 0.17552077 & 0.82447923 \\
\hline 33 & 0.21198361 & 0.78801639 \\
\hline 34 & 0.29388628 & 0.70611372 \\
\hline 35 & 0.45558605 & 0.54441395 \\
\hline 36 & 0.57216275 & 0.42783725 \\
\hline 37 & 0.67915149 & 0.32084851 \\
\hline 38 & 0.73330751 & 0.26669249 \\
\hline 39 & 0.77412768 & 0.22587232 \\
\hline 40 & 0.7814252 & 0.2185748 \\
\hline 41 & 0.82888647 & 0.17111353 \\
\hline 42 & 0.80903904 & 0.19096096 \\
\hline 43 & 0.82492339 & 0.17507661 \\
\hline 44 & 0.83268046 & 0.16731954 \\
\hline 45 & 0.83485189 & 0.16514811 \\
\hline 46 & 0.80818265 & 0.19181735 \\
\hline 47 & 0.79468166 & 0.20531834 \\
\hline 48 & 0.72204043 & 0.27795957 \\
\hline 49 & 0 & 0 \\
\hline 50 & 0 & 0 \\
\hline 51 & 0 & 0 \\
\hline 52 & 0 & 0 \\
\hline
\end{tabular}

